\title{
Enterprise Systems Meet Social BPM
}

\author{
Martin Molhanec \\ Czech Technical University in Prague \\ Faculty of Electrical Engineering, Department of e-Technology \\ molhanecafel.cvut.cz
}

\begin{abstract}
This article engages in issues of Enterprise Systems and SBPM (Social Business Process Management) influence, integration, joint evolution and reasons which cause these matters of fact. Afterwards, the Author describes his own approach based on extensions of WebRatio CASE tool, primarily targeted as a tool for supporting WebML method, to assist in modelling, developing and operating enterprise SBPM systems. Subsequently, the Author proposes several design components intended for BPM developers which can be easily used to create a SBPM system with features as a collaboration of users, dynamic changes of workflow in runtime, common cooperation through Facebook or Twitter, etc. In the end, the Author summarizes the paper, suggests questions and discusses future directions of implementation of Enterprise SBPM Systems, especially from the point of view of an employment of WebRatio CASE tool as an analytic and design tool as well as operating platform into one.
\end{abstract}

Keywords: Enterprise systems, BPM, BPMN, social networks, WebRatio, WebML, social features, web modelling, software engineering.

\section{Motivation}

Modern WOIS (Web Oriented Information Systems) strongly targeted for use inside a given enterprise or business domain represent a modern information operating platform for enterprise business processes running in it. For modelling of such complex WOIS there are several web oriented analytic methods, such as OOHDM, UWE, and the most develop method of them - WebML [1 and 2]. On the other hand, in the area of business systems the specialised business process modelling methods are used, such as BPMN [3], BORM [4] and Ontology [5]. It is evident that the ones analysing and modelling methods exist in the area of web engineering and the other methods exist in the area of business modelling. We may put down a question if there is any connection between these two types of analysing methods as well as if exist the methods and tools supporting both such different analysing and modelling approaches ever.

The last decade moved business into a very dynamic environment which is very liable to changes caused by global market situation, intensive competition and continuing dissemination of new technologies. Such changes must be supported not 
only by organisational structure, company workflow and business processes but also by information systems themselves.

In addition, a modern information system is highly complicated application. A complete analysis of that is traditionally required as a necessary part of first phase of software construction process. Nevertheless, not every time it is possible to make a final analysis as deeply as needed. As time goes on requirement changes constantly coming and such changes aren't often caught by analysis.

In recent years there has been an enormous increasing of Business Process Management (BPM) usage [6, 7, and 8]. One of the ways how to catch changing requirements is to use social BPM. It involves ordinary users to catch the changes and requirements. But it is not quite clear at present time what meaning the idea of social BPM is [9]. We will discuss this subject in more detail thereinafter.

We can summarize the subject so far as follows. Present-day BPMs are not just about modelling process, but no less, about collaborating of different users as well. Interested users need to communicate and cooperate during the course of model evolution. Finally, these users aren't usually skilled in business processes modelling subject at all in contrast to a present-day trend to involve nontechnical users to take a part in a development process too.

The rest of this paper is organized as follows. Next, in Section 2, we start off by defining the problem statement we must resolve. Section 3 describes WebML method and WebRatio CASE Tools, Section 4 explains connection between WebRatio CASE tool and BPMN notation, finally section 5 introduces our approach. After that, Section 6 gives the results of our work, i.e., our implementation of Social Features in WebRatio CASE tool, and finally, Section 7 summarizes the paper, suggests improvements and discusses future directions for research.

\section{Problem Statement}

As Clay Richardson says, the Social BPM is: "Processes developed and improved through the use of social technologies and techniques". This definition follow his personal view of it as a way of bringing a new wave of BPM suites, including process Wikis, Process Mashups and BPM-as-a-Service started a lot of activity on the web [9]. But there are other opinions of this subject, under mentioned, that have been collected from social BOM discussion on EbizQ [10].

According to Michael zur Muehlen: "Social is all about providing context, a rich environment of data points that a streamlined workflow would be lacking otherwise. The challenge is to make this context useful, both from a social networking perspective and from an unstructured data perspective", [9]. But, Tom Allanson explains that: "Social BPM is basically just collaborative business process management utilizing a collective network environment - it's about extending BPM access and decision-making to partners and select external parties without compromising the exclusivity of the core group", [Ibid.]. 
It can be seen that there is not only one right opinion about this subject. By the Authors, there are two large areas, in which the feature of social BPM can be implemented.

- The first one is a collaboration platform for developers, business analysts and other professionals around BPM.

- The second area is a collaboration platform for users of BPM systems.

In this paper we aim only at the second area of implementing social BPM features. There are several issues we must solve. One issue is how to make BPM modelling dynamic (so the model can change during running the system). Another issue is how to easily involve non-technical users so they can change the model, as it evolves in the time, without a special business modelling knowledge.

\section{WebML and WebRatio}

WebML [2] is the most developed web-method at the present time. As stated in the Wikipedia [1].

"WebML (Web Modeling Language) is a visual notation for designing complex data-intensive Web applications. It provides graphical, yet formal, specifications, embodied in a complete design process, which can be assisted by visual design tools, like WebRatio. This method has five models: structure, derivation, composition, navigation and presentation. These models are developed in an iterative process."

At first sight it looks like a process model is not included in the WebML concept or if you like, that any of the five different diagrams do not deals with the modelling of process domain of information systems. But, it is not true at all. The model of processes is included into a composite model of composition model and navigation model, jointly named as hypertext model in the WebML terminology.

Primarily, the hypertext model is targeted towards modelling, on the one hand, the network of navigations between the pages of certain web site, and, on the other hand, the composition of particular web pages from functional units, such as data unit, multi-date unit, index unit and many others, how is in detail described in WebML hypertext diagram notation documentation. An example of simple hypertext diagram is shown in (Fig. 1, example is taken from [11]).

Herein we put a very brief explanation of (Fig. 1); the example demonstrates a simple web site view denoted Product with four pages named: By category, Product details, Search and Images. All pages contain different units, for example, the page named Images contains the Product data unit and Enlarged images multi-data unit. But, we can also observe that there are the other units not included into any particular web page. These units are special process units, intended especially for data processing, but for other type of process activities as well.

We can point out, for example, login or logout units. As far as concerning the data process units, be specific, Add note, Add to cart and Update stock units, these units 
are especially target for inserting, modifying and deleting information records into database. Farther, we can observe that last two data process units are included in a special area named Add to cart transaction. This special type of area includes data process units subjected to database transaction.

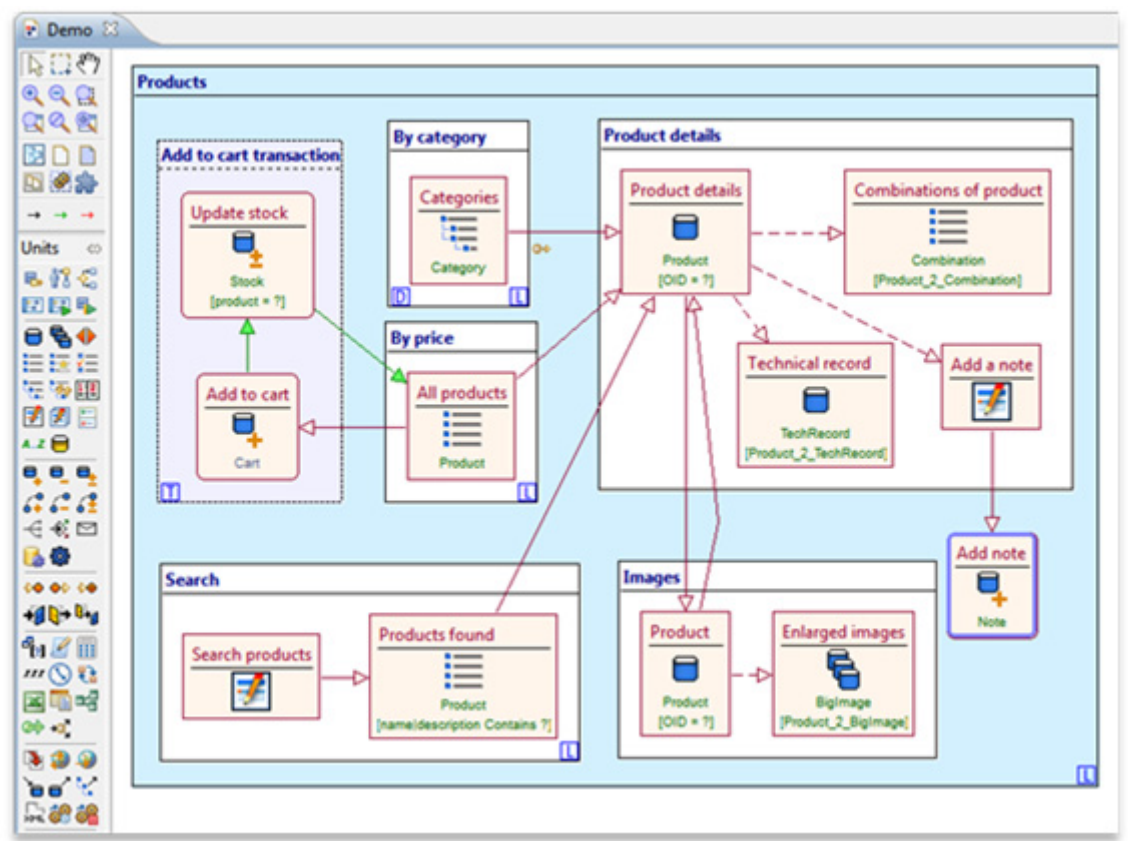

Fig. 1. WebML hypertext diagram - example

It is clear now that WebML diagram really can contain also process elements placed outside web pages on navigational paths between them. However, it has appeared that this combination of complex business logic and hypertext design of web site into one complex diagram is not a very efficient solution. Firstly, such diagram is exceedingly complex for easy understanding by developer; secondly, the process alias business portion of the system can be more easily modelled by standardized BPMN [3] notation with many advantages. In the next section we show how this idea of WebML and BPMN jointly modelling is implemented in WebRatio CASE tool.

\section{WebRatio and BPMN}

WebRatio [12] CASE tool is the one of the rarely existed CASE tools implementing the whole MDA process from beginning, i.e., from the data and process specification, to completion, i.e., to generation of the whole application. The last version 6.0 of WebRatio implements in one application both the WebML designer, and BPMN designer as well. 
Herein we put a very brief explanation of the whole development process with the WebRatio CASE tool. The WebML method, as well as, WebRatio CASE tool insists on MDD (Model Driven Development) approach, it means that all life cycle of product development is controlled by models. The WebRatio Model Driven development environment allowing capturing business requirements in abstract model, i.e., Computationally Independent Model (CIM), in terms of Model Driven Architecture (MDA) paradigm as is defined by OMG (Object Management Group) and automatically generates a full-featured, industrial-strength, business application. The whole process is divided into three steps as follows:

- Design the Model - is a step of development process concerning with creation and verification of application model. This model is based on user requirements and constrains flowing from legacy situation, standards, company guidelines, etc.

- Customize the Rules - is a step of tailoring our model to better fulfil our requirements in more details. We can implement is this step, for example, a checking of input and output parameters, implement a constraining of different business criteria, add an online help, and so on.

- Generate the Application - in this step the WebRatio generates the whole application. It is the most complicated task, totally hidden from the view of end user. There is, of course, a possibility to affect the mode of generation by some parameters.

Now we can focus on the first step of development, i.e., on the step of designing the model. We can observe that WebRatio includes two quite different diagrammatic instruments, (1) the first of them is a designer of standardized BPMN diagrams targeted modelling of business processes defined by the precedent analysis of business requirements, and (2) second, the special designer of WebML web-method modelling notation, targeted modelling navigations between web site pages, content of these pages by means of many specialized WebML units, and eventually processes others than processes follow from business requirements. The first type of model, i.e., the process model, strongly based on BPMN notation, is used to define:

- Organisation and roles

- Activities and assignments

- Business roles

- Business workflow

The second model, i.e., the application model, is based on WebML modelling language, and is used to define:

- Page contents

- Business logic 
- User interface \& Visual identity

- Integration

In the frame of whole development process the construction of the first model precedes the second one. By the Author's opinion, this conception of utilisation of two very different types of model, managed by two different and independents subjects is very inventive. This concept also shows quite clearly a difference between a business and informational process, the subject, not very frequently discussed generally.

There are four different perspectives of WebRatio tool development process as illustrated in the following text. We can observe that there are four different roles participating on development process, namely:

- Business analyst - creating a business model in BPMN based on users requirements

- Application/WebRatio Analyst - creating an application model in WebML based on users requirements, web site design guidelines and just created foregoing business model as well

- Web Designer - elaborating and completing the application model, as well as creating layout templates for all visual units of the system in order to produce a clear and well-arranged graphical appearance of all web pages of the web site

- Java Developer - developing and implementing custom components needed to implement all non-standard content, hybrid and process units of the model

The concept of Model-Driven Development Process implemented in WebRatio CASE tool consists from following four steps. We start with a specification of traditional BPMN process model. In the second step we manually enrich and extend this model to create a choreography model (extended BPMN). Further, we run an automatic transformation of BPMN to WebML, then; we possibly repeatedly manually refine produced WebML models. And finally, we run automatic code generation on J2EE platform. The whole process is shown in the following.

1. Business process (BPMN) specification

2. Choreography model (extended BPMN)

3. Application Model (WebML)

4. Generating Application (J2EE)

In the following we try explaining the most important step of the whole application development; a transformation from BPMN scheme to WebML scheme. The main question we need to explain herein is as follows, how we can generate the whole application specified in WebML from BPMN diagrams? To start we suppose following simple BPMN diagram (Fig. 2, example is taken from [11]) presenting a simple BPMN diagram of Product Catalogue Application. We see a business process borne by three business participant: Employee, Supervisor and Treasurer. The Employee performs Edit Report manual task, The Supervisor performs Review 
Report manual task and Treasurer performs Confirm Receipts manual task and Process Expanses service task.

The main principles of transformation process from BPMN to WebML are as follows:

- The manual tasks and gateways are not transformed at all

- The service tasks and gateways are transformed to operation module in WebML

- The user tasks and gateways are transformed to hybrid module in WebML

- There is generated one control site view for BPMN pool

- There is generated one site view for one BPMN line

The result of such transformation of Confirm Receipts manual task is shown in (Fig. 3). We see that the Confirm Receipts task is transformed into Confirm Receipts web page in WebML model with three WebML units: Info, Get Parameters and User Input. We can also observe the process units needed for input and output parameters passing, located in the diagram outside the Confirm Receipts web page.

In conclusion, the whole transformation of BPMN model into WebML model implemented in WebRatio CASE tool is complex and sophisticated, but really implementing the Model Driven Development paradigm in its entirety.

\section{Our Approach}

The approach we used to create a design support for inclusion of social features into a modelling and developing phase of Enterprise Systems, lies in the possibility to build custom units in WebRatio CASE tool [13]. By means of these custom units it is possible to extend a WebML modelling notation to fulfil our needs. Our extensions comprise the units dealing with some social aspects of business process management as discussed before.

WebML is built on very few, highly configurable concepts, which can be used to effectively analyse and design complex web applications for publishing, updating or processing its content. The key aspect of WebML is a capability to define a hypertext model of a web site consisting of pages, content units, and operation units, linked each other to form a design specification of the whole system.

However, the core units provided by WebML may not be sufficient for covering the entire spectrum of application requirements; moreover one may need to use his own specialized software components in the course of a web applications development. To support this purpose, WebRatio enables developers to implement so called custom units (also called plug-in units). A custom unit can be of type of content unit or operation unit and is defined by a developer, and is not, of course, included in the WebRatio standard installation. Thus, a custom unit is both similar and different to the standard unit.

A development of a custom unit covers all aspects of WebRatio CASE tool architecture, because a definition as well as an execution of the unit requires addressing both design-time and run-time issues. 
WebRatio CASE tool let developers to use their custom units in the course of web site development and these units will cooperate perfectly with standard units too. Since predefined WebML units are implemented in the same way as user's custom units, a user can start familiarising with the components of a custom unit by looking at those of the standard units.

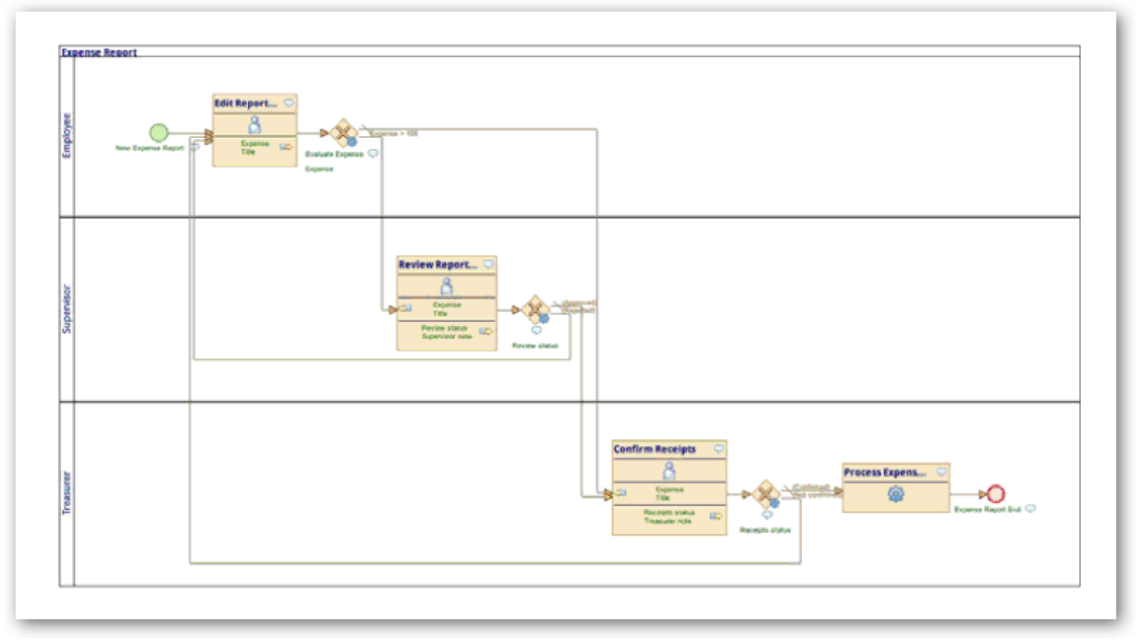

Fig. 2. BPMN model of the Product Catalogue Application

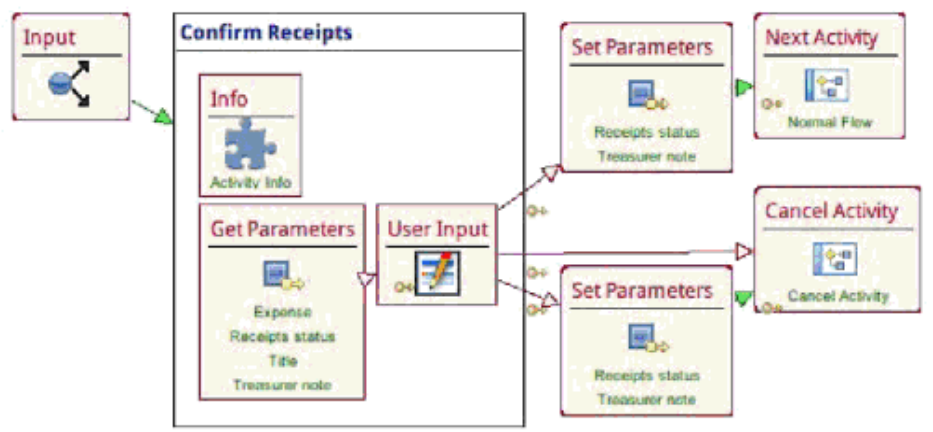

Fig. 3. Generated WebML hypertext for the Confirm Receipt activity

\section{Social Features Implemented in WebRatio}

At the beginning, we have introduced a question of what kind of social BPM features our work should support (development phase or run-time?). The final decision at the 
moment is to implement only run-time features. It gives the added value to WebRatio applications developers so their web systems will support BPM social features just by adding new units with abilities as follows.

- Login to the social network

- Add a comment/note to the process as anonymous.

- Add a comment/note to the process as logged user.

- Delete a comment/note from the process for logged user.

- Read a list of comments for the current process.

- Read a list of all comments for the current application.

We also have captured non-functional requirements are stated below.

- We are aimed on implementing social BPM features from run-time phase of an application life cycle.

- We must provide functionality for Facebook API.

- We need an extensibility of new social networks.

One of the ways how to extend functionality of WebRatio CASE tool is an utilisation of the concept of Custom Units (see preceding section). The concept of custom units is easily accessible to every user of WebRatio CASE tool. At the present we started with implementation of custom units covering only Facebook social network. Slight modification is needed to support other social networks (Twitter, LinkedIn). This modification only depends on API provided by particular social network provider. We have decided to implement only following functional types of custom units:

\section{Get Unit}

- Read a list of comments for the current process.

- Read a list of all comments for the current application.

\section{Post Unit}

- Add a comment/note to the process as anonymous.

- Add a comment/note to the process as logged user.

\section{Remove Unit}

- Delete a comment/note from the process for logged user.

An example of some Social Units included into a Master Page of synchronised BPM project is shown in Fig. Fig. 4. Subsequently, the Fig. 5 shows the login page for BPM testing scenario created for the purposes of project testing. Finally, the Fig. 6 shows how particular social units are included in the process detail of Open and Check $C V$ activity of our testing project. 


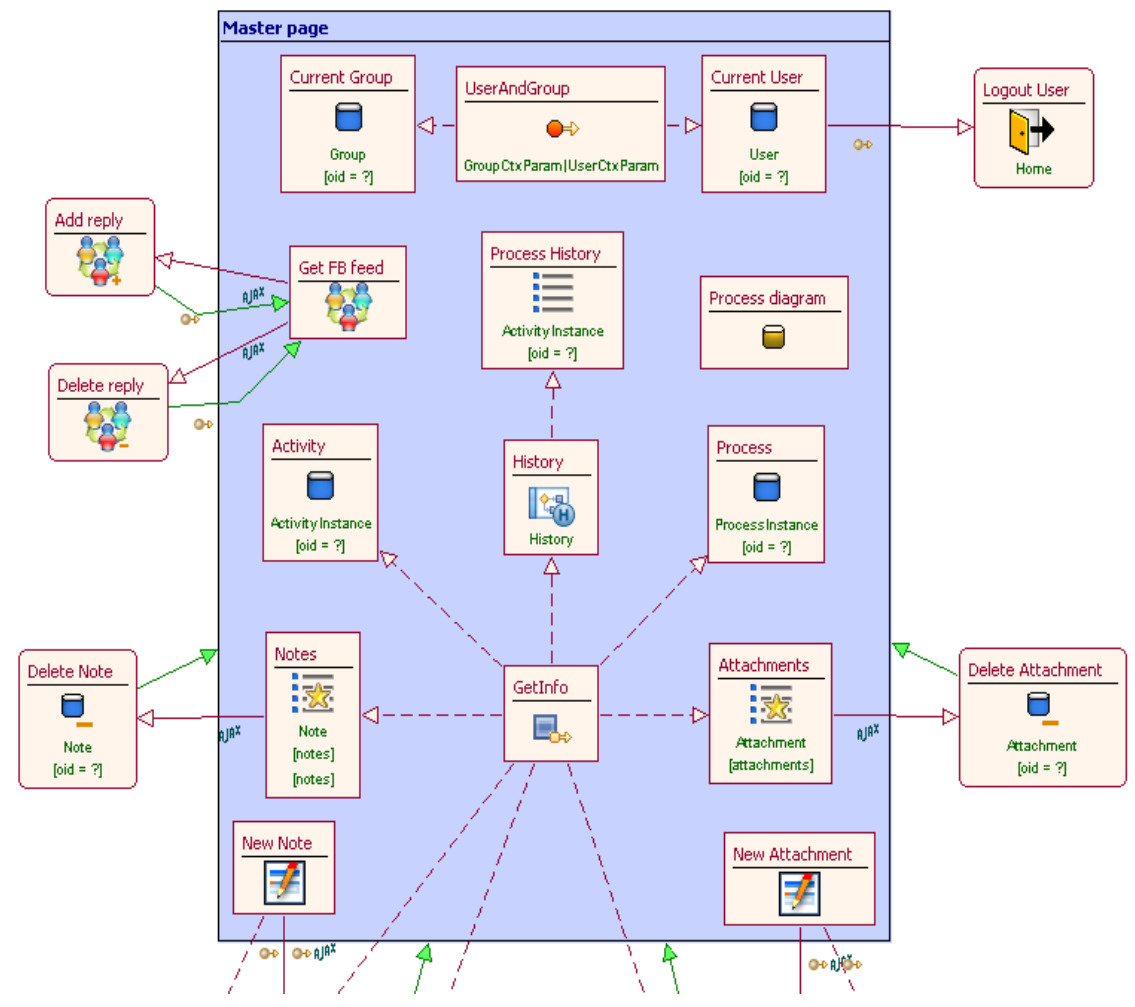

Fig. 4. Units implemented in BPM testing scenario - master page

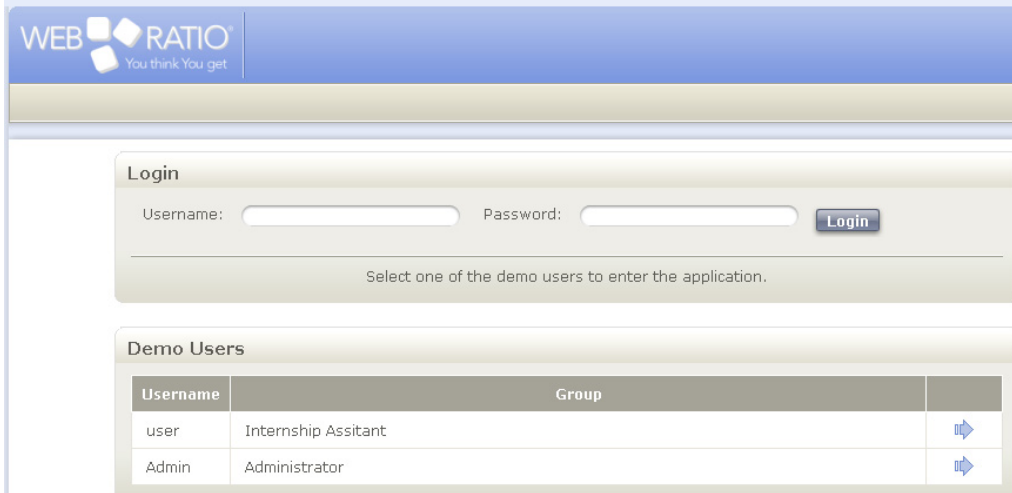

Fig. 5. Units implemented in testing scenario - login page 


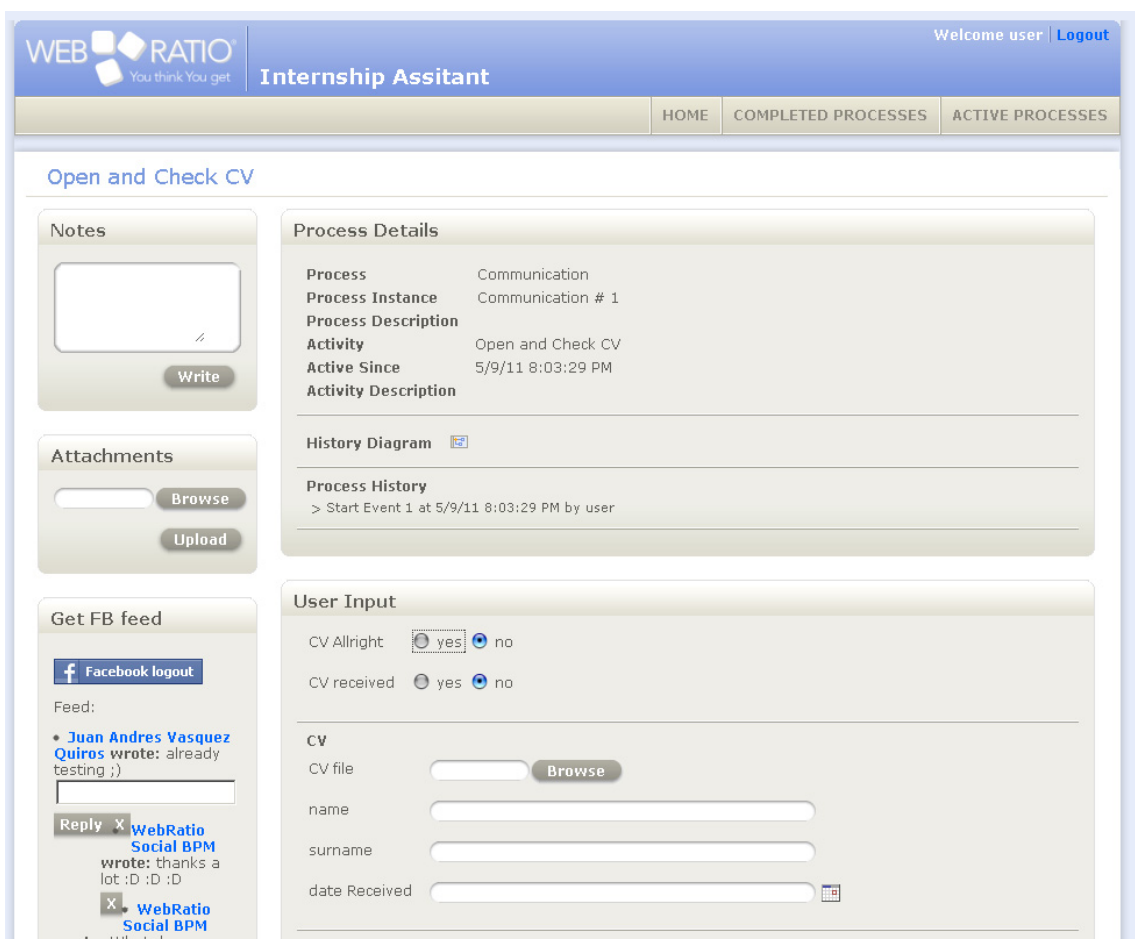

Fig. 6. Units implemented in testing scenario - process details with Social Units

\section{Conclusion and Future Work}

This work is partially realised on an output of the master thesis of Dominik Franěk [14], supervised by the Author of this contribution. Moreover, many ideas have been initiated as a result of discussion with a WebRatio development team member, Mr Marco Brambilla.

Planned future extensions cover a support for other social networks such as Twitter, LinkedIn. At present, only Facebook social network is supported and there is a strong need to add all popular social networks too.

Another direction of our future work would be an automatic generation of Social Units during a synchronisation of BPM project with Web project. But, this part can't be done without modifying a WebRatio source code and only in cooperation with WebRatio developer's team has it would be realised.

To summarize presenting article; we firstly explain the present-day necessity to enrich Business Process Management of Enterprise System of social-network features. Afterwards we show connections between WebML method and WebRatio CASE tool on one side and BPMN notation and social features on other side.

Further, we briefly describe a process of transformation from BPMN scheme to WebML scheme. Furthermore, we describe our implementation of some custom social units created for WebRatio CASE tool. Finally, we propose some directions of future Author's works. 
Acknowledgement. This research (work) has been partially supported by Ministry of Education, Youth and Sports of Czech Republic under research programs number MSM6840770017 and SGS projects number SGS10/267/OHK3/3T/13.

\section{References}

1. WebML at Wikipedia, http://en.wikipedia.org/wiki/WebML

2. WebML method, Home Page, http: / /www . webml . org/webml/page1. do

3. BPMN specification at OMG site, http: / / www . bpmn . org /

4. Brožek, J., Merunka, V., Merunková, I.: Organization Modeling and Simulation Using BORM Approach. In: Barjis, J. (ed.) EOMAS 2010. LNBIP, vol. 63, pp. 27-40. Springer, Heidelberg (2010)

5. Pergl, R.: Supporting Enterprise IS Modelling Using Ontological Analysis. In: Barjis, J., Eldabi, T., Gupta, A. (eds.) EOMAS 2011. LNBIP, vol. 88, pp. 130-144. Springer, Heidelberg (2011)

6. Becker, J., Rosemann, M., von Uthmann, C.: Guidelines of Business Process Modeling. In: van der Aalst, W.M.P., Desel, J., Oberweis, A. (eds.) BPM 2000. LNCS, vol. 1806, pp. 30-49. Springer, Heidelberg (2000)

7. Ko, R.K.L., Lee, S.S.G., Lee, E.W.: Business process management (BPM) standards: a survey. Business Process Management Journal 15(5), 744-791 (2009)

8. OMG. Business Process Model and Notation (BPMN) Specification 2.0. Object Management Group Inc. (March 2011)

9. InfoQ: Is There Social BPM?, http: / /www. infoq. com/news / $2010 / 05$ /SocialBPM (citated May 15, 2011)

10. Social BPM: Is It Social, or is It BPM? - ebizQ Forum, http: / /www. ebizq. net/blogs / ebizq_forum/2010/03/social-bpmis-it-social-or-is-it-bpm.php (citated May 15, 2011)

11. Butti, S.: A MDD approach to BPM, presentation online, http: //www.slideshare.net/stefano_butti/webratio-a-mddapproach-to-bpm-4872510

12. WebRatio, Home page, http: //www . webratio.com

13. Acerbis, R., Bongio, A., Brambilla, M., Butti, S.: WebRatio 5: An Eclipse-Based CASE Tool for Engineering Web Applications. In: Baresi, L., Fraternali, P., Houben, G.-J. (eds.) ICWE 2007. LNCS, vol. 4607, pp. 501-505. Springer, Heidelberg (2007)

14. Franěk, D.: Social BPM Features in Webratio tool, Master Theses, Czech Technical University in Prague (2011) 